\title{
PRESTASI BELAJAR MATEMATIKA DENGAN TGT DAN NHT PADA SISWA BERGAYA BELAJAR KINESTETIK
}

\author{
Ridam Dwi Laksono \\ FKIP, Universitas PGRI Madiun \\ email: ridam.dl@unipma.ac.id
}

\begin{abstract}
With the implementation of $K-13$, it is necessary to innovate learning models on the material, tools and how to deliver them. The purpose of this study is to find out whether the mathematics learning with TGT and NHT models that have been innovated according to the 2013 curriculum, whether students have the same learning achievement. Second, to find out the learning style as an internal factor of students, is there an influence on the achievements. Third, to find out the interaction between learning models and student learning styles on student achievement. This activity is carried out by means of quasi experiments. Student learning achievement as the dependent variable, learning models and learning styles as independent variables. Statistical analysis using two-way ANOVA. Student achievement data is taken using cognitive test instruments and classification of learning styles using learning style questionnaires. Obtained research results (1) student achievement on the TGT learning model is better than student achievement on the NHT learning model, (2) there is no influence of student learning styles on learning achievement, (3) there is an interaction between learning models with learning styles. Students with kinesthetic learning styles have higher achievement when learning with the TGT learning model, compared to students who have the same learning style on NHT learning.
\end{abstract}

Keyword: TGT, NHT, Learning Style, Peer Learning.

Abstrak: Dengan diberlakukanya $K-13$, perlu dilakukan inovasi model pembelajaran pada materi, perangkat dan cara penyampaiannya. Tujuan penelitian ini pertama untuk mengetahui apakah pembelajaran matematika dengan model TGT dan NHT yang telah diinovasi sesuai kurikulum 2013, siswanya memiliki prestasi hasil belajar yang sama. Kedua untuk mengetahui gaya belajar sebagai faktor internal siswa, apakah terdapat pengaruh terhadap prestasi yang dicapai. Ketiga untuk mengetahui interaksi antara model pembelajaran dengan gaya belajar siswa terhadap prestasi siswa. Kegiatan ini dilakukan dengan cara eksperimen kuasi. Prestasi belajar siswa sebagai variabel terikat, model pembelajaran dan gaya belajar sebagai variabel bebas. Analisis statistik menggunakan ANOVA dua jalan. Data prestasi hasil belajar siswa diambil dengan menggunakan instrumen tes kognitif dan klasifikasi gaya belajar menggunakan angket gaya belajar. Diperoleh hasil penelitian (1) prestasi belajar siswa pada model pembelajaran TGT lebih baik dari pada prestasi belajar siswa pada model pembelajaran NHT, (2) tidak terdapat pengaruh gaya belajar siswa terhadap prestasi belajar, (3) terdapat interaksi antara model pembelajaran dengan gaya belajar. Siswa dengan gaya belajar kinestetik, memiliki prestasi yang lebih tinggi saat belajar dengan model pembelajaran TGT, dibandingkan siswa yang memiliki gaya belajar yang sama pada pembelajaran NHT.

Kata kunci: TGT, NHT, Gaya Belajar, Pembelajaran teman sebaya.

\section{PENDAHULUAN}

Matapelajaran merupakan matapelajaran yang menjadi momok bagi siswa di setiap negara (Gokkurt et al., 2012). Pembelajaran matematika yang berlangsung di dalam kelas, melibatkan interaksi antara guru dan siswa. Kelas sebagai lingkungan belajar di sekolah tempat memfasilitasi seluruh siswa yang memiliki kemampuan yang heterogen 
satu dan lainnya (Munandar, 2009). Dalam pembelajaran di kelas yang heterogen, guru perlu model dan strategi pembelajaran yang dapat mengakomodasi heterogenitas siswa yang majemuk.

Kesulitan belajar yang dialami siswa di dalam kelas yang heterogen umum terjadi di setiap sekolah. Model pembelajaran kooperatif merupakan salah satu model yang berkembang di sekolah untuk memfasilitasi heterogenitas siswa yang majemuk (Purwati, 2010). Pembelajaran kooperatif berjalan dengan cara siswa saling bekerja bersama untuk mencapai tujuan bersama. Pembelajaran kooperatif juga merupakan pendekatan pengajaran di mana siswa berkemampuan tinggi dan berkemampuan rendah bekerja bersama untuk memecahkan masalah (Aziz \& Hossain, 2010). Dalam kurikulum 2013, terjadi beberapa pergeseran paradigma pembelajaran dibandingkan dengan KTSP. Menurut L.Hakim (2017) pembelajaran dalam K-13 lebih terintegrasi. Salah satunya ada kemiripan dengan Major approach to learning with a cognitive approach yang dikemukakan oleh Steppen N. Elliot. Didalamnya dikemukakan tiga hal pertama belajar haruslah meaningful (bermakna), kedua belajar haruslah discovery learning (belajar mendapatkan penemuan, cari tahu); Ketiga, belajar haruslah construtivism (belajar secara konstruktif menurut teori constructivism) (Hakim, 2017). Maka dalam hal ini, perlu modifikasi strategi pada konsep kooperatif yang sudah ada.

Modifikasi ini terjadi pada beberapa hal, pertama konten materi dalam pembahasan. Kedua strategi dalam penyampaian konten. Ketiga teknik menilai proses dan hasil belajar siswa. Model pembelajaran kooperatif yang dipilih pada kegiatan ini adalah pembelajaran matematika dengan model kooperatif TGT dan model kooperatif NHT. keduanya merupakan model pembelajaran kooperatif yang umum dan telah banyak dijalankan di sekolah sebelum K-13. Ketiga modifikasi yang dilakukan, utamanya terkait pada proses pemberian pengetahuan. Di kegiatan pembelajaran pada awal kedua strategi guru memberikan pengetahuan yang terkait pembelajaran dengan mengkaitkan secara kontekstual dengan kondisi terkini di sekitar siswa (Komsatun et al., 2013). Pada seluruh aspek pengetahuan yang disampaikan dikaitkan dengan informasi terkini yang ada di lingkungan masyarakat sekarang.

Pada kegiatan ini, juga dilakukan pengukuran gaya belajar siswa. Gaya belajar memiliki pengaruh dalam berfikir kritis matematika (Karim, 2014). Gaya belajar merupakan faktor struktural, yang jika diperhatikan dalam pendekatan pembelajaran dapat berpengaruh pada prestasi belajar (Marfu'ah, 2016). Gaya belajar merupakan kecenderungan siswa dalam proses memahami, mengingat dan mengasimilasi informasi yang didapatnya dalam proses belajar, untuk kemudian difahami dan digunakan dalam menyelesaikan permasalahan belajar yang di dapatnya, atau masalah dalam kehidupannya. Kecenderungan siswa ini merujuk pada dominansi faktor yang kebiasaan dalam diri siswa. Banyak siswa dalam belajar memerlukan dukungan internal dan eksternal, agar cara belajarnya dapat berhasil. Model pembelajaran merupakan salah satu cara yang di desain oleh guru agar siswa dapat belajar dengan gaya belajar siswa. Dengan mengetahui gaya belajar siswa selama proses pembelajaran berjalan, dapat dilihat daya dukungnya terhadap prestasi yang diperoleh. Selain itu interaksi model pembelajaran terhadap gaya belajar terhadap desain belajar sebagai pengembangan dapat dilakukan.

\section{METODE PENELITIAN}

Kegiatan ini dilaksanakan dengan eksperimen kuasi dengan membandingkan dua model pembelajaran yang berbeda. Desain faktorial yang digunakan $2 \times 3$. Dengan variabel bebas model pembelajaran dan gaya belajar, sedangkan variabel terikat prestasi siswa. Kelompok pertama mendapat pembelajaran dengan model TGT dengan jumlah siswa sebanyak 35 siswa. Kelompok kedua mendapat pembelajaran dengan model NHT sebanyak 33 siswa. Instrumen pengambilan data menggunakan soal uji kognitif dan angket 
gaya untuk kedua variabel bebas. Selain itu selama proses pembelajaran disertai dengan rencana pembelajaran dan LKS yang telah di sesuaikan dengan kondisi kontekstual lingkungan sekolah siswa.

Klasifikasi gaya belajar, dilakukan dengan angket gaya belajar. Dengan menggunakan angket kecenderungan gaya belajar, siswa di identifikasi menjadi tiga gaya belajar. Ketiga gaya belajar tersebut yaitu gaya belajar Visual, gaya belajar Auditori, dan gaya belajar Kinestetik (Peng L, 2002). Hasil angket kemudian dihitung dan simpulkan keputusan berdasarkan skor tertinggi pada salah satu kategori deskriptor yang ada (Sari, 2014). Masing - masing gaya belajar ini melekat diri siswa, dan dapat mengalami asimilasi dengan memberikan pengalaman belajar baru selama penelitian (Klement, 2014).

Seluruh data yang diperoleh dari pengukuran prestasi kognitif dan angket gaya belajar dipasangkan sesuai dengan siswa yang mengikuti. Selanjutnya analisis data dilakukan dengan menggunakan anava dua jalan dengan memperhatikan uji prasyarat parametrik. Kemudian dilakukan uji lanjut jika terdapat beda yang signifikan pada masing - masing variabel serta interaksinya.

\section{HASIL DAN PEMBAHASAN}

Setelah proses pembelajaran dilaksanakan, dilakukan pengukuran prestasi kognitif dan pengambilan data angket gaya belajar. Hasil uji prasyarat pada normalitas dan homogenitas ditampilkan pada Tabel 1 dan Tabel 2 . Hasil pengujian dengan SPSS pada Tabel 1 menunjukkan jika data terdistribusi normal. Sedangkan pada Tabel 2 menunjukkan bahwa sampel homogen. Pada Tabel 3, ditunjukkan deskripsi data yang diperoleh. Hasil Tabel 1 dan Tabel 2, menunjukkan sampel memenuhi prasyarat uji prametrik, sehingga uji anava dua jalan bisa dilanjutkan.

Hasil uji Anava dua jalan dengan menggunakan SPSS ditunjukkan pada Tabel 4. Dari tabel menujukkan nilai sig. yang kurang dari 0,05 hanya ada dua dari tiga uji yang disajikan. Pengambilan keputusan uji setiap nilai hasil uji SPSS dibandingkan dengan nilai 0,05 .

Hasil uji yang pertama menunjukkan nilai sig. 0,004. Karena nilai sig. kurang dari 0,05 hal ini mengakibatkan $\mathrm{H}_{0}$ di tolak, dengan keputusan terdapat perbedaan prestasi belajar siswa yang dikenai model pembelajaran $T G T$ dan $N H T$. Hasil uji yang kedua nilai sig. sebesar 0,741 . Pada uji ini karena nilai sig lebih dari 0,05 hal ini mengakibatkan $\mathrm{H}_{0}$ diterima, dengan keputusan tidak terdapat beda prestasi belajar pda siswa yang memiliki gaya belajar visual, gaya belajar auditori dan gaya belajar kinestetik. Hasil uji ketiga nilai sig. sebesar 0,003. Hasil Uji yang didapat kurang dari 0,05 , dengan keputusan $\mathrm{H}_{0}$ ditolak, dengan keputusan terdapat interaksi antara model pembelajaran TGT dan NHT terhadap gaya belajar siswa.

Pada uji pertama dengan keputusan terdapat beda prestasi, maka perlu diperhatikan model pembelajaran mana yang memiliki dampak lebih baik terhadap prestasi belajar siswa. Memperhatikan Tabel 3, didapat rerata TGT terhadap NHT yaitu 50.51 dan 44.27. Dengan demikian pembelajaran dengan model TGT memberikan rerata prestasi belajar siswa lebih tinggi dibandingkan dengan rerata prestasi belajar siswa dengan model pembelajaran $N H T$.

Tabel 1. Test Of Normality

\begin{tabular}{|c|c|c|c|c|c|c|c|}
\hline & \multirow[b]{2}{*}{ Model } & \multicolumn{3}{|c|}{ Kolmogorov-Smirnov $^{\mathrm{a}}$} & \multicolumn{3}{|c|}{ Shapiro-Wilk } \\
\hline & & Statistic & $d f$ & Sig. & Statistic & $d f$ & Sig. \\
\hline \multirow{2}{*}{$\underline{\text { Prestasi }}$} & TGT & .125 & 35 & .187 & .962 & 35 & .271 \\
\hline & $\overline{\mathrm{NHT}}$ & .123 & 33 & $.200^{*}$ & .962 & 33 & .293 \\
\hline
\end{tabular}

a. Lilliefors Significance Correction 
*. This is a lower bound of the true significance.

Tabel 2. Levene's Test of Equality of Error Variance ${ }^{a}$

Dependent Variable: Prestasi

\begin{tabular}{cccc}
\hline$F$ & $d f 1$ & $d f 2$ & Sig. \\
\hline 1.960 & 5 & 62 & .097 \\
\hline
\end{tabular}

Tests the null hypothesis that the error variance of the dependent variable is equal across groups. a. Design: Intercept + model + gaya_belajar + model $*$ gaya_belajar

Tabel 3. Descriptive Statistics

Dependent Variable: Prestasi

\begin{tabular}{lccrr}
\hline \multirow{3}{*}{ Model } & \multicolumn{1}{c}{$\begin{array}{c}\text { Gaya_ } \\
\text { Belajar }\end{array}$} & Mean & Std. Deviation & \multicolumn{1}{c}{$N$} \\
\hline TGT & Visual & 46.9474 & 7.40476 & 19 \\
\cline { 2 - 5 } & Auditori & 48.6667 & 12.75408 & 6 \\
\cline { 2 - 5 } & Kinestetik & 58.4000 & 7.35149 & 10 \\
\cline { 2 - 5 } & Total & 50.5143 & 9.65697 & 35 \\
\hline NHT & Visual & 45.3333 & 13.91128 & 15 \\
\cline { 2 - 5 } & Auditori & 48.4167 & 13.85285 & 12 \\
\cline { 2 - 5 } & Kinestetik & 33.3333 & 11.21903 & 6 \\
\cline { 2 - 5 } & Total & 44.2727 & 14.13169 & 33 \\
\hline Total & Visual & 46.2353 & 10.61462 & 34 \\
\cline { 2 - 5 } & Auditori & 48.5000 & 13.11600 & 18 \\
\cline { 2 - 5 } & Kinestetik & 49.0000 & 15.21403 & 16 \\
\cline { 2 - 5 } & Total & 47.4853 & 12.35240 & 68 \\
\hline
\end{tabular}

Tabel 4. Test of Between - Subjects Effects Dependent Variable: Prestasi

\begin{tabular}{lrrrrr}
\hline Source & $\begin{array}{c}\text { Type III Sum of } \\
\text { Squares }\end{array}$ & $d f$ & Mean Square & \multicolumn{1}{c}{ F } & \multicolumn{1}{c}{ Sig. } \\
\hline Corrected Model & $2486.721^{\mathrm{a}}$ & 5 & 497.344 & 3.986 & .003 \\
\hline Intercept & 124245.425 & 1 & 124245.425 & 995.728 & .000 \\
\hline Model & 1140.413 & 1 & 1140.413 & 9.140 & .004 \\
\hline gaya_belajar & 75.136 & 2 & 37.568 & .301 & .741 \\
\hline model $*$ gaya_belajar & 1648.229 & 2 & 824.114 & 6.605 & .003 \\
\hline Error & 7736.264 & 62 & 124.778 & & \\
\hline Total & 163553.000 & 68 & & & \\
\hline Corrected Total & 10222.985 & 67 & & & \\
\hline
\end{tabular}

a. $R$ Squared $=.243$ (Adjusted $R$ Squared $=.182$ ) 


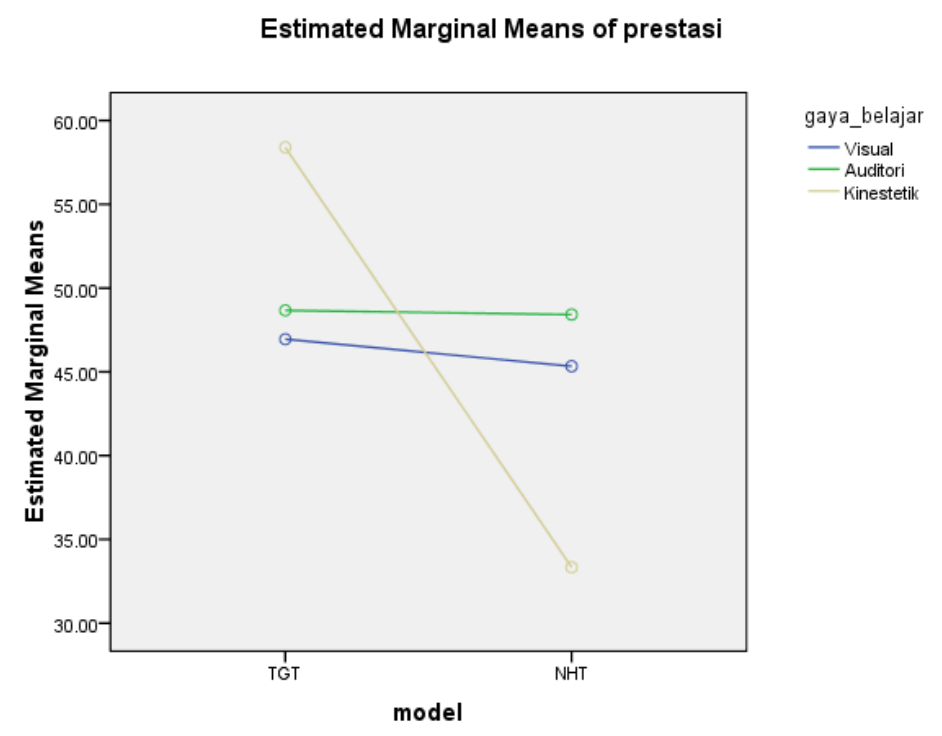

Gambar 1. Estimated Marginal Means of Prestasi

Pada uji ketiga keputusan statistik menunjukkan adanya interaksi model pembelajaran dengan gaya belajar. Dari Tabel 3, dapat kita perhatikan pada gaya belajar kinestetik di kedua model pembelajaran, terdapat beda rerata prestasi belajar siswa. Pada pembelajaran TGT, siswa dengan gaya belajar kinestetik memiliki nilai 58.4. Sedangkan pada pembelajaran NHT, siswa dengan gaya belajar kinestetik memiliki rerata nilai 33,33. Interaksi kedua model terhadap gaya belajar dapat di lihat pada gambar 1. Dari gambar 1, dapat kita lihat, titik - titik rerata prestasi ketiga gaya belajar. Enam titik yang dihubungkan menjadi garis gaya belajar diantara dua model pembelajaran. Nampak pada garis rerata pada prestasi gaya belajar kinestetik terjadi perubahan yang drastis. Siswa dengan gaya belajar kinestetik, memiliki rerata prestasi yang tinggi pada model pembelajaran TGT, sedangkan pada model pembelajara NHT rerata prestasinya sangat rendah. Nampak berbeda dibandingkan dengan dua rerata prestasi lainnya yaitu gaya belajar visual dan gaya belajar auditori.

Uji pertama menunjukkan adanya perbedaan prestasi belajar siswa yang mendapat model pembelajaran TGT dan NHT. Rerata prestasi belajar siswa lebih tinggi TGT dibandingkan NHT. Hal ini dapat disimpulkan jika proses pembelajaran dengan menggunakan Model TGT dapat memberikan prestasi belajar siswa lebih baik daripada NHT. Fenomena yang terjadi selama proses pembelajaran pada TGT dan NHT yaitu pada interaksi siswa selama prose KBM. Dalam pembelajaran TGT, interaksi siswa menjadi kunci proses konstruksi pengetahuan dalam disi siswa (Komsatun et al., 2013). Interaksi ini terjadi tidak hanya saat KBM di kelas, namun sepanjang pekan setelah game setiap pertemuan terjadi hingga turnamen akhir pekan selesai berlangsung. Setelah siswa menerima penjelasan dan ekplorasi dari guru, siswa berdiskusi dalam kelompok. Kemudian siswa mempersiapkan diri untuk mengikuti games di akhir pertemuan pembelajaran. Informasi yang dimiliki oleh siswa yang tidak lengkap saat penjelasan dari guru, akan dibantu sesama teman sejawat saat diskusi kelompok dan setelah mengetahui jawaban benar di akhir game. Selama proses ini terjadi pembelajaran teman sebaya, mengakibatkan setiap siswa tertantang untuk mempersiapkan diri saat turnamen di akhir pekan. Siswa yang memiliki konstruksi pengetahuan lebih lengkap akan membantu siswa yang memiliki kekurangan konstruksi pengetahuan. Sehingga mereka berubah dari siswa yang memiliki kesulitan melihat 
pembelajaran menjadi siswa yang mampu melihat pembelajaran selama kolaborasi pembelajaran teman sebaya berlangsung (Slavin, 2005).

Dalam pembelajaran NHT, siswa diminta untuk lebih banyak bertanggungjawab atas materi yang harus dikuasainya (Dahlia et al., 2017). Hal ini menjadi kendala pada siswa yang tidak memiliki konstruksi pengetahuan yang lengkap saat penjelasan materi dari guru. Proses presentasi dan tanya jawab yang tidak berimbang karena konstruksi pengetahuan yang tidak lengkap mengakibatkan siswa kesulitan dalam presentasi. Walaupun guru dalam memberikan pengetahuan sudah secara kontekstual, namun proses konstruksi pengetahuan secara internal tidak lengkap, siswa akan mengalami kesulitan dalam tanya jawab setelah presentasi. Agar dapat memperdalam pemahaman melalui NHT, setiap siswa dalam proses pembelajaran harus bisa menguasai materi yang menjadi bagian penugasannya. agar proses pemahaman yang dalam dapat berjalan, dan NHT baru efektif meningkatkan prestasi siswa (S.Y. Nursyamsi \& Corembima, 2016).

Kendala dalam menyampaikan presentasi dan kesulitan menjawab pertanyaan dari teman kelompok lain, menjadi salah satu pemicu miskonsepsi. Sehingga di akhir tanya jawab saat presentasi, guru perlu menjelaskan kembali dan menunjukkan kesalahan dalam presentasi dan tanya jawab. Interaksi antar siswa dalam satu kelompok sangat bergantung pada fungsi mental individu yang terkumpul secara kolektif (Slavin, 2005). Fungsi untuk saling membantu agar pembelajaran teman sebaya dapat terjadi terhalang dengan beban pemahaman masing masing individu tugas pada satu topik. Karena setiap orang terbebani dengan penugasan presentasi pada suatu topik tertentu. Mereka tidak bisa saling bertukar ide untuk saling memahami antar topik pada awal - awal periode KBM. karena terbebani dengan penilaian dilakukan saat penampilan awal, banyak siswa yang sudah tampil tidak dapat melakukan perbaikan skor. Pembenahan kesalahan konsep materi pembelajaran dalam tanya jawab setelah presentasi siswa di sesi nomor awal sebagian besar bergantung kepada penjelasan guru di akhir tanya jawab saat presentasi. Untuk itu perolehan skor secara keseluruhan setiap kelompok rendah. Setiap orang pada masing - masing kelompok memiliki waktu untuk belajar bersama hanya setelah orang terakhir meampilkan presentasinya sebelum uji kompetensi dilakukan.

Pada uji ketiga menunjukkan adanya interaksi antara model pembelajaran dengan gaya belajar. Khususnya pada siswa dengan gaya belajar kinestetik di kedua model pembelajaran. Rerata Prestasi belajar siswa dengan gaya belajar kinestetik pada model pembelajaran TGT lebih baik daripada rerata prestasi belajar siswa dengan gaya belajar kinestetik pada model pembelajaran NHT. Perbedaan ini secara statistik terlihat sangat signifikan pada Gambar 1. Gaya belajar sebagai faktor struktural dalam pendekatan pembelajaran, menjadi penting untuk di perhatikan oleh guru. Kedua model pembelajaran memberikan dampak yang berbeda pada siswa dengan gaya belajar yang sama. Pada kegiatan ini, siswa dengan gaya belajar kinestetik memiliki hasil rerata prestasi yang beda pada kedua model pembelajaran.

Ungkapan game dan turnamen yang disampaikan oleh guru di awal pembelajaran TGT dalam siswa dalam kelas yang heterogen, menjadi sebuah stimulan dalam benak siswa. Walaupun bentuk game yang diberika ialah mengerjakan soal, atau quiz yang disesuaikan tingkatan kemampuan masing masing siswa. Hal ini secara mental menantang siswa. Kesempatan interaksi siswa sebagai kunci efektivitas model pembelajaran TGT dapat berlangsung dengan baik. Kesempatan pertama ini terjadi saat proses diskusi kelompok. Setiap siswa dalam kelompok memperlajari semua topik secara bersamaan dari penyampaian oleh guru. Siswa yang dapat mengikuti pembelajaran dan materi yang diajarkan oleh guru, bisa saling mengajari siswa yang kesulitan melihat pembelajaran dan materi yang di berikan oleh guru pada saat diskusi kelompok. 
Kesempatan kedua terjadi setelah game dilaksanakan. Interaksi siswa memperhatikan hasil koreksi setelah pelaksanaan game. Hasil koreksi jawaban game didiskusikan siswa dalam kelompok. Mereka mencari dimana letak kekeliruan dalam proses mengerajakan game yang diberikan. Hal ini menjadikan siswa yang sebelumnya menjawab kurang tepat, mengenali dimana letak kekeliruannya, sehingga saat turnamen di akhir pekan, mereka sudah siap untuk mengerjakan dan berpindah meja.

Penugasan pada model pembelajaran NHT berbentuk presentasi menjadikan siswa dalam kelas yang heterogen merasa terbebani. Setiap siswa terbebani untuk memahami satu topik secara mandiri. Pembelajaran teman sebaya yang mengakomodir siswa yang mampu melihat pembelajaran dan materi yang diberikan kepada guru, tertahan karena masing masing harus menguasai pemahaman pada topik yang ditugaskan kepaadanya. Sehingga interaksi siswa yang mampu untuk mengajarkan kepada siswa yang tidak dapat melihat pembelajaran dan materi yang diberikan oleh guru, tidak leluasa terjadi. Hal ini karena pemahaman siswa sebagai kunci efektivitas model pembelajaran NHT, terjadi tidak merata pada setiap pembelajaran. Interaksi siswa setelah penjelasan dari guru setelah presentasi siswa, menjadi satu satunya jawaban bagi siswa yang telah tempil presentasi. Penjelasan dari guru ini, biasanya terjadi saat jam pelajaran akan usai. Sehingga interaksi tidak terjadi dalam proses KBM, selain itu siswa dalam kelompok semakin terbebani untuk mempersiapkan presentasi selanjutnya. Sehingga penjelasan yang telah disampaikan oleh guru pada presentasi sebelumnya tidak menjadi fokus perhatian siswa.

Siswa dengan gaya belajar kinestetik biasanya lambat dalam berbicara, senang dengan permainan yang melibatkan mental dan fisik, tidak dapat berdiam diri dalam waktu yang relatif lama, mereka melibatkan indera peraba dalam aktivitas belajarnya untuk menghafal, memberi isyarat dengan mendekat serta memfokuskan perhatian ketika berbicara dengan orang, memperhatikan penampakan fisik dan aktif bergerak, mampu mengingat dengan memperhatikan dan melakukan gerakan, gesture dan isyarat tubuh menjadi salah satu cara menyampaikan pesan, umunya memiliki tulisan tangan yang kurang rapi. selalu ingin beraktivitas dalam segala suasana (Ophilia Papilaya \& Huliselan, 2016). Dari keseluruhan unsur kesenangan ciri siswa dengan gaya belajar kinestetik dapat kita bandingkan kondisinya pada masing - masing model pembelajaran. Pada model pembelajaran TGT, bentuk pembelajaran diwujudkan dalam game atau permainan akan membuat siswa dengan gaya belajar kinestetik akan tertarik. Sedangkan dalam pembelajaran NHT, siswa lebih banyak pada bentuk memahami materi pembelajaran, kemudian di presentasikan kembali. Kemudian dilanjutkan dengan tanya jawab. Siswa dengan gaya belajar kinestetik akan mengalami kesulitan, sebab lebih cenderung lambat untuk berbicara, sehingga tanya jawab tidak berlangsung dengan baik.

Pada pembelajaran TGT, Jika siswa dengan gaya belajar kinestetik tidak mampu, mereka dapat berinteraksi dengan siswa lain yang mampu. proses ini terjadi pada belajar dengan teman sebaya. Mereka dapat mengikutinya pada kedua kesempatan belajar yang ada. Saat diskusi kelompok, dan pada saat hasil koreksi game di berikan. Pada pembelajaran NHT kesempatan ini tidak muncul. Waktu diskusi sebelum presentasi dan setelah dijelaskan oleh guru tidak dapat dimanfaatkan oleh siswa dengan gaya belajar kinestetik. Interaksi yang sesuai dengan gaya belajar kinestetik dengan siswa lainnya untuk bertukar pendapat tidak dapat terjadi. Sehingga fungsi mental individu yang menciptakan keterikatan dalam kelompok sebagai hasil kolaborasi sulit untuk terwujud.

Pada pembelajaran TGT, semua interaksi dapat di rasakan oleh siswa dengan gaya belajar kinestetik. Karena berjalan tanpa beban. Hasil game yang diberikan oleh guru, menjadi bahan diskusi dan berinteraksi antar siswa. Hal ini membuka kesempatan bagi siswa dengan gaya belajar kinestetik mengeksplorasi 
semua kebiasaanya dalam interaksi belajarnya dengan siswa lain. Berbeda dengan NHT, beban penguasaan dan pemahaman materi sebelum presentasi menghalangi siswa untuk berinteraksi dengan leluasa.

\section{SIMPULAN}

Pada eksperimen perbandingan dua model pembelajaran ini terdapat beda pencapaian prestasi belajar. Model pembelajaran TGT siswa memiliki prestasi belajar lebih baik dibandingkan dengan siswa yang belajar dengan model NHT. Interaksi siswa dalam pembelajaran TGT dapat berjalan dengan baik karena dua kesempatan siswa untuk berinteraksi terwujud. Prestasi belajar pada siswa dengan masing - masing gaya belajarnya, tidak terdapat perbedaan. Ketiganya memiliki prestasi belajar siswa yang sama.

Terdapat interaksi antara model pembelajaran dengan gaya belajar. Siswa dengan gaya belajar yang sama, memiliki prestasi yang berbeda di kedua model pembelajaran. Siswa dengan gaya belajar kinestetik mengalami hambatan pada pembelajaran NHT. Kesempatan berdiskusi yang ada tidak dapat memberikan kesempatan siswa dengan gaya belajar kinestetik untuk mengeksplorasi kebiasaanya dalam belajar. Sehingga proses belajar siswa dengan gaya belajar kinestetik terhambat.

Diskusi sebagai bentuk interaksi antar siswa dalam belajar perlu di strategikan dengan baik. Agar dapat mengakomodasi semua faktor gaya belajar siswa dalam proses KBM. Sebagai faktor struktural dalam pendekatan pembelajaran, gaya belajar siswa perlu di identifikasi lebih awal oleh guru. Sehingga dalam pengambilan keputusan dalam menerapkan metode, strategi dan tindakan, dapat mengakomodir seluruh siswa yang heterogen dalam kelas.

\section{DAFTAR RUJUKAN}

Aziz, Z., \& Hossain, M. A. (2010). A comparison of cooperative learning and conventional teaching on student's achievement in secondary mathematics. Procedia - Social and
Behavioral Sciences, 9, 53-62. https://doi.org/10.1016/j.sbspro.2010. 12.115

Dahlia, E., Syahrilfuddin, \& Lazim, N. (2017). IMPLEMENTATION OF COOPERATIVE LEARNING MODELTYPE NUMBER HEADS TOGETHERS ( NHT ) TO IMPROVE STUDENT RESULT LEARNING OF SCIENCE CLASS IV SD NEGERI 10 BENGKALIS PENERAPAN MODEL PEMBELAJARAN KOOPERATIF TIPE NUMBER HEADS TOGETHERS ( NHT ) UNTUK MENINGKATKAN HA. Jurnal Online Mahasiswa FKIP UNRI, 4(1), $1-13$.

https://jom.unri.ac.id/index.php/JOM FKIP/article/view/18483

Gokkurt, B., Dundar, S., Soylu, Y., \& Akgun, L. (2012). The Effects of Learning Together Technique Which is based on Cooperative Learning on Students' Achieevement in Mathematics Class. Procedia - Social and Behavioral Sciences, 46, 34313434.

https://doi.org/10.1016/j.sbspro.2012. 06.079

Hakim, L. (2017). Analisis Perbedaan Antara Kurikulum. Jurnal Ilmiah Didaktika, 17(2), 280-292. https://doi.org/10.22373/jid.v16i1.59 0.5

Karim, A. (2014). Pengaruh gaya belajar dan sikap siswa pada pelajaran matematika terhadap kemampuan berpikir kritis matematika. Jurnal Formatif, 4(3), 188-195.

Klement, M. (2014). How do my Students Study? An Analysis of Students' of Educational Disciplines Favorite Learning Styles According to VARK Classification. Procedia - Social and Behavioral Sciences, 132, 384-390. https://doi.org/10.1016/j.sbspro.2014. 04.326 
Komsatun, S., Riyadi, \& Sujadi, I. (2013). Eksperimentasi Model Pembelajaran Teams Games Tournament Dan Numbered Heads Together Dengan Pendekatan Matematika. Jurnal Elektronik Pembelajaran Matematika, 1(7), 682-689.

Marfu'ah, Z. I. H. (2016). Hubungan Gaya Belajar Visual, Auditorial Dan Kinestetik Dengan Hasil Belajar Matematika (Studi Asosiatif pada Siswa Kelas XI Sekolah Menengah Kejuruan Negeri 9 Surakarta Tahun Pelajaran 2015/2016). Universitas Muhammadiyah Surakarta.

Munandar, U. (2009). Pengembangan Kreativitas Anak Berbakat (3rd ed.). Rineka Cipta.

Ophilia Papilaya, J., \& Huliselan, N. (2016). Identifikasi Gaya Belajar Mahasiswa. Universitas Pattimura, 15 no. $1(1), \quad 8$. ejournal.undip.ac.id/index.pho/psikol ogi/article/download/12992/9731

Purwati, H. (2010). Keefektifan Pembelajaran Matematika Berbasis Penerapan Tgt Berbantuan Animasi Grafis Pada Materi Pecahan Kelas Iv. Aksioma: Jurnal Matematika Dan Pendidikan Matematika UPGRIS Semarang, $\quad$ 1(2). https://doi.org/10.26877/aks.v1i2/Sep tembe. 57

S.Y. Nursyamsi, P. S. O. B. E. S. U. of M. I., \& Corembima, A. D. (2016). The Effect Of Numbered Heads Together ( Nht ) Learning Strategy On The Retention Of Senior High School
Studentsin Muara .... European Journal If Education Studies, 2(5), 47-58.

https://doi.org/10.5281/zenodo.15445 0

Sari, A. K. (2014). Analisis Karakteristik Gaya Belajar Vak ( Visual , Auditorial , Kinestetik ) Mahasiswa Pendidikan. Jurnal Ilmiah Edutic, 1(1), 1-12. https://journal.trunojoyo.ac.id/edutic/ article/download/395/369

Slavin, R. E. (2005). Cooperative Learning Teori, Riset dan Praktik. In Zubaedi (Ed.), Allyman Bacon (15th ed.). Penerbit Nusa Media. http://www.buneido.co.jp/aste/aste84.html 
102 JURNAL PENDIDIKAN EDUTAMA, Vol.7, No.2 Juli 2020 